\title{
Form one students' engagement with computer games and its effect on their academic achievement in a Malaysian secondary school
}

\begin{abstract}
The main purpose of the study was to address the association between computer games and students' academic achievement. The exceptional growth in numbers of children playing computer games, the uneasiness and incomplete understanding foundation when starting the discussion on computer games have stimulated this study to be conducted. From a survey conducted on 236 form one students in one of the Malaysian secondary school, 75.8 percent were gamers. Playing computer games seemed to be more stereotypically boy's activity with 91.3 percent of the boys engaged in computer games compared to 54.1 percent among the girls. They spent an average of 8.47 hours per week playing computer games. Parents and teachers' concern about computer games was not something that went unwarranted as an overall result was predicting computer games as having negative associations with students' academic achievement. However, in-depth analyses by combinations of classes done step by step indicated that the initial results could be overruled by students from the last class, whom need extra attentions. As a conclusion, the findings in this study suggest some interesting yet ultimately weak associations between playing computer games and students' academic achievement. Nevertheless, caution is warranted in making any generalization as looking at the population as a whole will be different from its components. The generalizability of this study's findings is limited by the nature of the sample. Even so, blaming computer games for the students' bad academic performance in school is unjustified as there are many more other factors to look into before finding computer games as the scapegoat.
\end{abstract}

Keyword: Computer games, Academic achievements, Time spent playing computer games, Gamers and non-gamers 